\title{
Clinical, Radiographic and Blood Gas Alterations in Dogs with Acute Respiratory Distress Syndrome
}

\author{
V. Tamilselvan, M. Balagangatharathilagar*, M. Chandrasekar, \\ D. Sumathi and S. Kavitha \\ Department of Veterinary Clinical Medicine, Madras Veterinary College, \\ Vepery, Chennai-600 007, India \\ Tamil Nadu Veterinary and Animal Sciences University, India \\ *Corresponding author
}

\section{A B S T R A C T}

Keywords

ARDS, Dogs,

Hypoxemia,

Respiratory

alkalosis,

Pulmonary

infiltrates,

Mechanical

ventilation

Article Info

Accepted:

12 March 2021

Available Online:

10 April 2021
Acute respiratory distress syndrome (ARDS) is a clinical condition following a diffuse inflammatory insult to the lung parenchyma and generally occurs secondary to a primary disease process. The clinical criteria for ARDS are acute onset of respiratory distress, bilateral pulmonary infiltration on thoracic radiographs, hypoxemia and absence of clinical evidence of left atrial hypertension. Twenty three dogs with ARDS were recruited in this study. Dogs presented with criteria for ARDS had respiratory distress, tachypnea, labored breathing at rest and cyanosis. Blood gas analysis revealed hypoxemia, hypercapnia, hypocapnia, respiratory alkalosis and increased alveolar to arterial oxygen gradient in these cases. Increased pulmonary interstitial and bilateral multilobar alveolar infiltrates were detected in thoracic radiography. This study concluded that ARDS leads to primary and secondary inflammatory changes leads to hypoxemia and abnormal pulmonary infiltrative patterns.

\section{Introduction}

Acute respiratory distress syndrome (ARDS) is a clinical syndrome occurs as a result of diffuse inflammatory insult to the lung parenchyma secondary to a primary disease process. The American-European Consensus Conference led to the first broad consensus of definitions in 1994, where ARDS was defined as acute onset of hypoxemia with a ratio of partial pressure of arterial oxygen to fraction of inspired oxygen $\left(\mathrm{PaO}_{2} / \mathrm{FiO}_{2}\right) 200 \mathrm{~mm} \mathrm{Hg}$, with bilateral infiltrates on thoracic radiographs in the absence of left atrial hypertension (Bernard et al., 1994). In 2007, the first clinically based veterinary consensus 
definitions on the syndromes of acute lung injury (VetALI) and acute respiratory distress syndrome (VetARDS) were published and effort to improve the validity and reliability of definitions and diagnostic criteria of this condition, the Berlin Definition of ARDS was proposed in 2012. The clinical criteria were established for ARDS by Boiron et al., (2019) included (1) acute onset of respiratory distress, (2) bilateral pulmonary infiltrates on chest radiographs, (3) hypoxemia defined as a $\mathrm{PaO}_{2} / \mathrm{FiO}_{2}$ (P/F) ratio of $\leq 300$ and in the absence of arterial blood gas analysis, an $\mathrm{SpO}_{2} / \mathrm{FiO}_{2}(\mathrm{~S} / \mathrm{F})$ ratio $\leq 315$, and (4) absence of clinical evidence of left atrial hypertension and cases were excluded if thoracic radiographs or echocardiography evidenced left sided congestive heart failure.

Improved understanding of the pathophysiology of ARDS has shown that ARDS is mainly triggered by systemic inflammation which can leads to multiple organ dysfunction syndrome. Several inciting conditions for ARDS have been reported, including trauma, sepsis, pneumonia, pancreatitis, and transfusions (Balakrishnan et al., 2017).

Clinical signs ARDS may be delayed for 2 to 3 days after the inciting event triggers the pulmonary inflammatory response. Manifestations of ARDS may include progressive hypoxemia, respiratory distress, tachypnea and cyanosis. Physical examination observation may include orthopnea, harsh lung sounds progressing to crackles and foamy pink expectorate in severe cases (Declue and Cohn 2007).

Arterial blood gas interpretation and thoracic radiographs are the best indicators of ARDS. Blood gas analysis is mainly important to assess oxygenation, ventilation and acid-base balance thus clarifying the physiological condition of the patient. Blood gas analysis has been documented to be useful in assessing the severity of pulmonary diseases, such as pneumonia, pulmonary fibrosis, and brachycephalic airway syndrome in dogs which triggers the secondary acute respiratory distress syndrome in dogs. Blood gas abnormalities including hypoxemia, respiratory alkalosis and increased alveolar to arterial oxygen gradient are common with this syndrome (Wilkins et al., 2007).

\section{Materials and Methods}

\section{Selection of dogs with ARDS}

Dogs presented with respiratory emergencies and abnormal paradoxical breathing were subjected to $\mathrm{SpO}_{2}$ measurement. Blood gas analysis was performed in dogs with $\mathrm{SpO}_{2}$ less than 90\%. Oxygen therapy and thoracic radiography was taken in dogs with $\mathrm{PaO}_{2}$ less than $80 \mathrm{mmHg}$. Finally dogs with pulmonary infiltration and $\mathrm{PaO}_{2}$ less than $60 \mathrm{mmHg}$ were included in this study for further evaluation to identify the primary and systemic risk factors of ARDS. Hematobiochemical and blood smear studies were also performed for the diagnosis of systemic conditions. Ten apparently healthy dogs presented to Madras Veterinary College Teaching Hospital for vaccination and routine health checkup were included as apparently healthy controls.

\section{Arterial blood gas analysis}

Blood samples were collected in a heparinised syringe from the femoral artery using a heparinised syringe with caution to avoid air bubbles within the sample and the needle was immediately covered by placing a rubber stopper over the needle tip. Arterial blood was analyzed by blood gas analyzer (EPOC, Siemens) immediately after sample collection. $\mathrm{PaO}_{2}$ values were classified as normoxemia $\left(\mathrm{PaO}_{2} \geq 80 \mathrm{mmHg}\right)$, mild hypoxemia (60 $\leq \mathrm{PaO}_{2}<80 \mathrm{mmHg}$ ), moderate hypoxemia (45 
$\leq \mathrm{PaO}_{2}<60 \mathrm{mmHg}$ ), or severe hypoxemia $\left(\mathrm{PaO}_{2}<45 \mathrm{mmHg}\right) . \mathrm{PaCO}_{2}$ values were classified as normocapnia $\left(32<\mathrm{PaCO}_{2}<43\right.$ $\mathrm{mmHg})$, hypocapnia $\left(\mathrm{PaCO}_{2} \leq 32 \mathrm{mmHg}\right)$, hypercapnia $\left(\mathrm{PaCO}_{2} \geq 43 \mathrm{mmHg}\right)$.

\section{Thoracic radiographs}

Thoracic radiography of the lungs was performed in dogs after initial stabilization with preoxygenation and mild sedation with butorphanol $0.2 \mathrm{mg} / \mathrm{kg}$ administered either intramuscularly or intravenously. Right lateral, left lateral and ventrodorsal radiographs of the thorax were taken. Dogs with pulmonary interstitial and diffuse bilateral pulmonary alveolar infiltrates were taken into study. Whereas cases with radiographic evidences of cardiomegaly or distended pulmonary vessels suggestive of congestive heart failure were not included.

\section{Results and Discussion}

\section{Identification of risk factors in the dogs with ARDS}

Based on the ARDS criteria mentioned above, twenty three dogs were included in this study and ten apparently healthy dogs served as controls. The risk factors identified for primary ARDS $(\mathrm{n}=10)$ were aspiration pneumonia $(\mathrm{n}=4)$, pulmonary contusions $(n=3)$, drowning $(n=2)$ and Brachycephalic airway syndrome (BAS) $(n=1)$. Risk factors identified for Systemic ARDS $(n=13)$ were sepsis ( $\mathrm{n}=5)$ and Systemic Inflammatory Response Syndrome (SIRS) $(\mathrm{n}=8)$.

\section{Clinical manifestations}

Tachypnea and dyspnea with abnormal paradoxical respiration were observed in all the cases. Crackles and louder breath sounds were observed in dogs with aspiration pneumonia. Dogs with trauma and / or accident had rib fracture and evinced pain during physical examination.

\section{Thoracic radiography}

Radiographic changes vary based on the severity and stage of the syndrome. In thoracic radiography diffuse bilateral pulmonary multilobar infiltrates were seen and predominantly caudo dorsal lung lobe infiltrations were observed (Fig 1 and Fig 2)

\section{Arterial blood gas analysis}

The findings of the arterial blood gas analysis were presented in the table 1 . All the dogs with ARDS showed hypoxemia with hypocapnia or hypercapnia, respiratory alkalosis, metabolic acidosis and increased alveolar to arterial oxygen gradient.

ARDS represents a complex reaction to primary pulmonary and systemic inflammatory factors. The pathological features recorded in ARDS were initial inflammatory or exudative phase followed by a proliferative phase and finally a fibrotic phase (Silversides and Ferguson 2012). ARDS is characterized by high-permeability edema or noncardiogenic pulmonary edema resulting from an increase in extravascular leakage of water from lung parenchyma due to primary pulmonary vascular injury to the endothelium or primary alveolar epithelial injury (Kelmer et al., 2012).

The diagnosis of ARDS is based on clinical criteria and these have been modified in human medicine since the original definition was developed in 1994. In veterinary medicine, the definition of ARDS was published in 2007. Thoracic radiography is the most commonly used tools in veterinary medicine to diagnose pulmonary edema. In this study the presence of pulmonary capillary leak showed bilateral multilobar alveolar 
infiltrates without cardiomegaly on thoracic radiographs were observed. A study of human patients reported thoracic radiographs had a sensitivity of $73 \%$, specificity of $70 \%$, and a negative predictive value of 0.47 for ARDS diagnosis (Fan et al., 2018).

Blood gas analysis provide information about both acid-base status and pulmonary function to give the initial stabilization for the patients. Four key values are provided from the arterial blood gas analysis include blood $\mathrm{pH}$, partial pressures of oxygen $\left(\mathrm{PaO}_{2}\right)$ and carbon dioxide $\left(\mathrm{PaCO}_{2}\right)$ and bicarbonate concentration $\left(\mathrm{HCO}_{3}\right)$ (Hunter 2001). The normal $\mathrm{PaO}_{2}$ in $\mathrm{dog}$ is $80-110 \mathrm{~mm} \mathrm{Hg}$. Hypoxemia is defined as a $\mathrm{PaO}_{2}$ of less than $80 \mathrm{~mm} \mathrm{Hg}$ at sea level, while a $\mathrm{PaO}_{2}$ of less than $60 \mathrm{~mm} \mathrm{Hg}$ is considered severe hypoxemia. Mechanical ventilation is needed for patients with severe hypoxemia despite oxygen therapy or patients with a $\mathrm{PaO}_{2}$ of less than $60 \mathrm{~mm} \mathrm{Hg}$ (Hopper and Powell 2013). $\mathrm{PaO}_{2} / \mathrm{FiO}_{2}$ (PF) ratios were used to determine ARDS in all the dogs. Normal animals breathing room air with an $\mathrm{FiO}_{2}$ of 0.21 is measured $\mathrm{PaO}_{2}$ is between 85 and $100 \mathrm{~mm}$ $\mathrm{Hg}$, which results in a PF ratio of 400 to 500 (Balakrishnan and Tong, 2020). As a thump rule the normal $\mathrm{PaO}_{2}$ should be roughly 5 times that of the $\mathrm{FiO}_{2}$. For example, an animal breathing $50 \%$ oxygen should have a normal $\mathrm{PaO}_{2}$ around $250 \mathrm{mmHg}$. The $\mathrm{PaO}_{2}$ ratio for this patient would be $250 / 0.5$, or 500 (Rieser, 2013). In this study patients with ARDS criteria had average $\mathrm{PaO}_{2}$ value $55 \mathrm{~mm} \mathrm{Hg}$ in which the $\mathrm{PaO}_{2} / \mathrm{FiO}_{2}$ ratio $(55 / 0.21$ or 261). Pulse oximetry is used as a surrogate for arterial blood gas analysis and the pulse oximetry probe were placed in ear pinna, digits, tongue, tail and skin fold in the abdomen. Preliminary evaluation of the $\mathrm{SpO}_{2} / \mathrm{FiO}_{2}$ ratio in dogs found that this ratio correlated well with the $\mathrm{PaO}_{2} / \mathrm{FiO}_{2}$ ratio in a population of dogs requiring assessment of oxygenation (Calabro et al., 2013). In people with ARDS, $\mathrm{SpO}_{2} / \mathrm{FiO}_{2}$ ratios of 235 and 315 were found to correlate with $\mathrm{PaO}_{2} / \mathrm{FiO}_{2}$ ratios of 200 and 300, respectively (Rice et al., 2007).

Table.1 Arterial Blood gas analysis of dogs with ARDS

\begin{tabular}{|c|c|c|c|c|}
\hline ABG Parameters & $\begin{array}{c}\text { Group I } \\
\text { Primary } \\
\text { ARDS }\end{array}$ & $\begin{array}{l}\text { Group II } \\
\text { Systemic } \\
\text { ARDS }\end{array}$ & $\begin{array}{c}\text { Group III } \\
\text { Apparently } \\
\text { healthy dogs }\end{array}$ & F Value \\
\hline pH & $7.42 \pm 0.09$ & $7.41 \pm 0.02$ & $7.39 \pm 0.06$ & $0.684^{\mathrm{NS}}$ \\
\hline $\mathrm{pCO}_{2}(\mathrm{mmHg})$ & $21.18 \pm 0.57^{\mathrm{a}}$ & $22.57 \pm 1.36^{\mathrm{a}}$ & $37.34 \pm 0.82^{b}$ & $60.439^{* *}$ \\
\hline $\mathrm{pO}_{2}(\mathrm{mmHg})$ & $58.39 \pm 1.06^{\mathrm{a}}$ & $57.62 \pm 1.35^{\mathrm{a}}$ & $90.39 \pm 0.89^{a}$ & $238.02^{* *}$ \\
\hline $\mathrm{cSO}_{2}$ & $85.63 \pm 0.51^{\mathrm{a}}$ & $86.03 \pm 0.67^{\mathrm{a}}$ & $98.91 \pm 0.18^{b}$ & $179.26^{* *}$ \\
\hline A-a gradient(mmHg) & $30.37 \pm 1.47^{b}$ & $30.97 \pm 1.28^{b}$ & $14.21 \pm 1.19^{\mathrm{a}}$ & $50.941^{* *}$ \\
\hline $\mathrm{PaO}_{2} / \mathrm{FiO}_{2}$ & $252.63 \pm 24.13^{a}$ & $270.19 \pm 5.05^{\mathrm{a}}$ & $472.76 \pm 16.19^{b}$ & $69.325^{* * *}$ \\
\hline cTCO & $23.19 \pm 1.36^{b}$ & $15.17 \pm 1.05^{\mathrm{a}}$ & $26.69 \pm 0.67^{c}$ & $35.274^{* * *}$ \\
\hline
\end{tabular}

The values bearing same superscript did not differ significantly.

${ }^{*} \mathrm{p}<0.05$-significant, $* * \mathrm{p}<0.01$-highly significant and ${ }^{\mathrm{NS}} \mathrm{p}>0.05$-non-significant 
Fig.1 Lateral radiographs of the thorax from a dog with acute respiratory distress syndrome. Note the diffuse, severe caudo dorsal lung lobe interstitial to alveolar pattern without signs of cardiac enlargement.

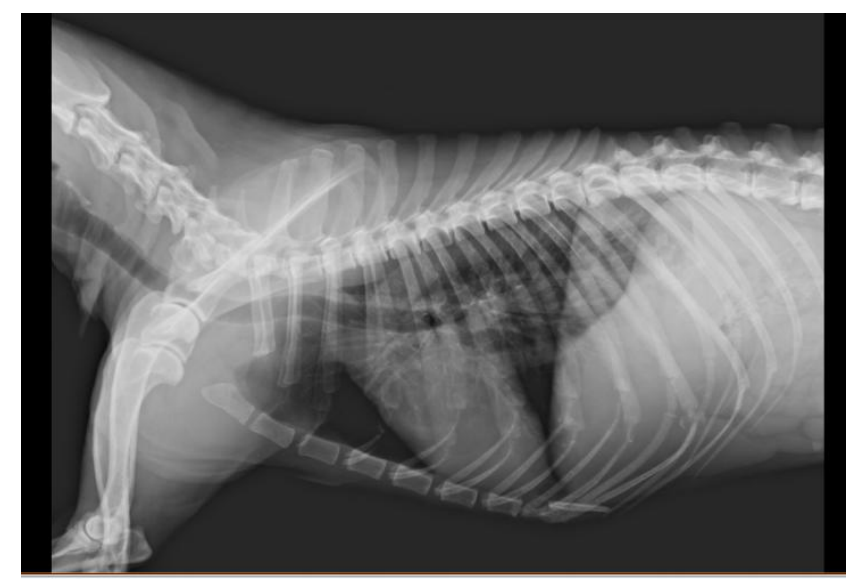

Fig.2 Ventrodorsal radiograph of the thorax from a dog with acute respiratory distress syndrome. Note the bilateral cranial lung lobe alveolar pattern without signs of cardiac enlargement.

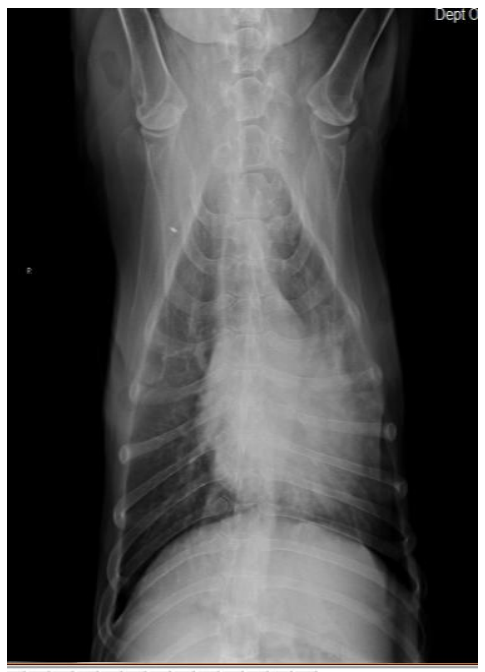

The respiratory alkalosis is characterized by a decrease in the $\mathrm{PaCO}_{2}$ concentration results in a compensatory decrease in $\mathrm{HCO}_{3}$. Common causes of respiratory alkalosis in critically ill dogs include stimulation of peripheral chemoreceptors in response to hypoxemia, pulmonary disease, and direct stimulation of the respiratory center include heatstroke, CNS disease, drugs, sepsis (Proulx, 1999).

Respiratory acidosis is characterized by a decrease in $\mathrm{pH}$ and increase in $\mathrm{PCO}_{2}$ often in conjunction with a compensatory increase in bicarbonate and base excess. Respiratory acidosis is generally the result of respiratory failure and hypoventilation. The main causes of respiratory acidosis include severe pulmonary edema, pulmonary thromboembolism, pneumonia, asthma, chronic obstructive pulmonary disease (McGrotty and Brown, 2013).

Normal physiologic difference in the partial pressure of oxygen in the alveoli $\left(\mathrm{PAO}_{2}\right)$ and 
the arterial blood $\left(\mathrm{PaO}_{2}\right)$ is called as the alveolar to arterial (A-a) gradient (Fanelli et al., 2013). Alveolar-arterial (A-a) gradient can be calculated from arterial blood gas and may help in differentiating the reasons of hypoxemia.

A normal A-a gradient is less than 15 to 25 $\mathrm{mm} \mathrm{Hg}$. A-a gradient provide a clinically useful in evaluating the pulmonary parenchymal disease, mainly in situations where the $\mathrm{PaCO}_{2}$ is variable or abnormal when serial blood gases are being compared (Balakrishnan and Tong, 2020). (A-a) $\mathrm{O}_{2}=150$ $-\mathrm{PaCO}_{2} / 0.8$ is the formula used to derive (Aa) gradient.

Blood gas analysis and thoracic radiography is needed for early diagnosis of the syndrome. SIRS, sepsis and aspiration pneumonia were the most common risk factors associated with ARDS, suggesting that earliest diagnosis and therapeutic interventions of sepsis and aspiration pneumonia may reduce the mortalities due to ARDS in dogs.

\section{References}

Balakrishnan, A., K.J. Drobatz and D.C. Silverstein, 2017. Retrospective evaluation of the prevalence, risk factors, management, outcome, and necropsy findings of acute lung injury and acute respiratory distress syndrome in dogs and cats: 29 cases (2011-2013), J. Vet. Emerg. Crit. Care,27(6): 662-673.
Boiron, L., K. Hopper and A. Borchers, 2019. Risk factors, characteristics, and outcomes of acute respiratory distress syndrome in dogs and cats: 54 cases, $J$. Vet. Emerg. Crit. Care,29(2): 173179.

Calabro, J. M., J. E. Prittie and D. A. D. Palma, 2013. Preliminary evaluation of the utility of comparing $\mathrm{SpO} 2 / \mathrm{FiO} 2$ and $\mathrm{PaO} 2 / \mathrm{FiO} 2$ ratios in dogs, J. Vet. Emerg. Crit. Care,23(3): 280-285.

Declue, A. E. and L. A. Cohn, 2007. Acute respiratory distress syndrome in dogs and cats: A review of clinical findings and pathophysiology: State-of-the-Art Review, J. Vet. Emerg. Crit. Care, 17(4): 340-347.

Hopper, K. and L. L. Powell, 2013. Basics of mechanical ventilation for dogs and cats, Vet. Clin. North Am. - Small Anim. Pract.,43(4): 955-969.

McGrotty, Y. and A. Brown, 2013. Blood gases, electrolytes and interpretation 1. Blood gases, In Pract., (2): 59-65.

Parent, C., L.G. King, L.M. Walker and T.J. Van Winkle, 1996. Clinical and clinicopathologic findings in dogs with acute respiratory distress syndrome: 19 cases (1985-1993), J. Am. Vet. Med. Assoc.,208(9): 1419-1427.

Sabino, C. V., M. Holowaychuk and S. Bateman, 2013. Management of acute respiratory distress syndrome in a French Bulldog using airway pressure release ventilation., J. Vet. Emerg. Crit. Care (San Antonio).,23(4): 447454.

\section{How to cite this article:}

Tamilselvan, V., M. Balagangatharathilagar, M. Chandrasekar, D. Sumathi and Kavitha, S. 2021. Clinical, Radiographic and Blood Gas Alterations in Dogs with Acute Respiratory Distress Syndrome. Int.J.Curr.Microbiol.App.Sci. 10(04): 51-56. doi: https://doi.org/10.20546/ijcmas.2021.1004.006 